\title{
EXTRAFISCALIDADE E CAPACIDADE CONTRIBUTIVA: A AMPLIAÇÃO DA NOÇÃO DE JUSTIÇA FISCAL PARA ALÉM DA CAPACIDADE CONTRIBUTIVA.
}

\author{
Everton das Neves Gonçalves* \\ Lyza Anzanello de Azevedo**
}

Resumo: O trabalho trata da extrafiscalidade e da capacidade contributiva ampliando a noção de justiça fiscal. Como objetivo geral, destaca que a justiça fiscal pode ser mitigada em vista do uso extrafiscal dos tributos em detrimento da capacidade contributiva. Especificamente, objetiva alertar para a necessidade de equilíbrio econômico-jurídico-fiscal visando o bem econômico social priorizando a justiça fiscal Trata-se de pesquisa qualitativa, de método dedutivo e com recurso à análise bibliográfica e documental. Conclui que a capacidade contributiva deve ser observada e a extrafiscalidade deve ser instrumental de justiça econômico-política para a inclusão social segundo o Princípio da Eficiência Econômico-Social (PEES).

Palavras chave: Direito e Economia; Análise Econômica do Direito; Extrafiscalidade; Capacidade Contributiva e Direito Tributário.

\section{EXTRA FISCALITY AND CONTRIBUTING CAPACITY: THE EXPANSION OF THE NOTION OF FISCAL JUSTICE BEYOND THE CONTRIBUTING CAPACITY.}

\begin{abstract}
The work deals with extrafiscality and contributing capacity, expanding the notion of fiscal justice. As a general objective, it highlights that fiscal justice can be mitigated by extrafiscality use of taxes in detriment of contributing capacity. Specifically, it aims to alert to the need for economic-legal-fiscal balance aiming at the social economic good prioritizing fiscal justice It's qualitative research, a deductive method and with the use of bibliographic and documentary analysis. It concludes that the contributing capacity must be observed and extrafiscality should be instrumental in economic-political-justice for social inclusion according to the Principle of Economic and Social Efficiency (PESE).
\end{abstract}

Key Words: Law and Economics; Economic Analysis of Law; Extrafiscality; Contributing Capacity and Tax Law.

\footnotetext{
* Doutor em Direito Econômico pela Universidade Federal de Minas Gerais (UFMG/MG); Doctor en Derecho Internacional Económico por la Universidad de Buenos Aires (UBA/ Bs. As.) Argentina; Mestre em Direito, na área de Instituições Jurídico-Políticas, pela Universidade Federal de Santa Catarina (UFSC/SC); Especialista em Comércio Exterior e Integração Econômica no MERCOSUL pela FURG/RS; Graduado em Direito pela Unianchieta de Jundiaí/SP e em Ciências Econômicas pela Universidade Federal do Rio Grande (FURG/RS); Especialista em Administração Universitária pela FURG/RS; Professor Titular credenciado no Programa de Pós-Graduação em Direito da Universidade Federal de Santa Catarina (PPGD/UFSC); Pesquisa Análise Econômica do Direito e Direito Econômico; Coordenador do Centro de Estudos Jurídico-Econômicos e de Gestão para o Desenvolvimento (CEJEGD) do Centro de Ciências Jurídicas (CCJ/UFSC). E-mail: evertong @ vetorial.net

** Graduada em Ciências Econômicas pela Universidade do Estado de Santa Catarina (UDESC/SC) e, em Direito pela Universidade do Sul de Santa Catarina (UNISUL/SC); Mestre em Direito e Doutoranda pela Universidade Federal de Santa Catarina (UFSC/SC). E-mail: lyzabyba@gmail.com
} 


\section{INTRODUÇÃO}

Em 05 de outubro de 2020, a Constituição da República Federativa do Brasil (CRFB/88) completará seus 32 anos de existência; tal fato caracteriza verdadeira conquista da democracia brasileira; manifestação progressista de inclusão social e base jurídica para o País que se reconstrói política, jurídica e socialmente em momento delicado (início dos anos vinte do Século XXI). Em 1988, para além da socialdemocracia brasileira, já grassava, no Planeta, a experiência neoliberal de Margaret Thatcher, Helmut Kohl e Ronald Reagan. Até o presente momento, já são mais de uma centena de Emendas Constitucionais que desfiguram, sensivelmente, o Texto Magno original de 1988. De fato, pontos sensíveis do Constitucionalismo de 1988 foram alterados, mormente, flexibilizando as relações de produção no País, os monopólios públicos, as prerrogativas do Estado em real avanço do poder econômico privado. Diversas foram as alterações do Texto Magno a suscitar efetivas mudanças na economia, na política e na sociedade Nacional. As reformas políticas e sociais que ocorreram no Brasil na década de 1980 culminaram na elaboração da Constituinte de 1988, a qual avançou sobremaneira na esfera dos direitos sociais, porém, no seu Capítulo Tributário, manteve praticamente a estrutura da Emenda ${ }^{\circ} .18$ de 1966.

Não há como negar, entretanto, que a CRFB/88 provocou mudanças substanciais no Sistema Constitucional Tributário Brasileiro, como a modernização dos impostos, a descentralização de receitas e a evolução no campo das limitações ao poder de tributar. No tocante a este último quesito, $v . g$., destaca-se, a graduação dos impostos segundo a capacidade econômica dos contribuintes, prevista no art. 145, § $1^{\circ}$ do Texto Magno de 1988.

Nesse contexto, a pesquisa visa demonstrar aspectos da evolução, nos últimos 30 anos, no tratamento normativo do Princípio da Capacidade Contributiva que, embora essencial para o alcance da justiça fiscal, pode ser mitigado quando em conflito com a aplicação de tributos extrafiscais. A partir dessa análise pretende-se estabelecer a importância fundamental da extrafiscalidade na busca por objetivos estatais em prol da coletividade, observando a ponderação de princípios em casos concretos com o estudo da jurisprudência dos Tribunais pátrios. A pesquisa utiliza o método dedutivo, sendo os meios majoritariamente bibliográficos e, quanto aos fins, verifica-se como descritiva e explicativa. Estrutura-se, portanto, a partir do estudo da capacidade contributiva, da extrafiscalidade dos tributos e da verificação do tratamento do tema nos Tribunais Pátrios. 


\section{CAPACIDADE CONTRIBUTIVA}

A inserção do respeito à capacidade contributiva na cobrança de impostos remonta ao livro A Riqueza das Nações ${ }^{1}$ do economista Adam Smith. Ao tratar sobre o sistema tributário o referido autor deixa claro que os tributos além de poderem incidir apenas sobre três fontes distintas: renda, lucro e salários; deveriam, inicialmente, respeitar a capacidade do contribuinte, isto é, "[...] em proporção ao rendimento de que cada um desfruta [...]" ${ }^{2}$ - princípio da equidade da tributação.

Outrossim, o recolhimento dos impostos deveria ser realizado no momento mais conveniente para o contribuinte. Dessa maneira, o imposto cobrado sobre o arrendamento da terra ou aluguel de casas seria cobrado no mesmo período em que se costumava pagar os arrendamentos e aluguéis, bem como os impostos sobre bens de consumo deveriam ser cobrados diretamente do consumidor na medida em que comprasse suas mercadorias. Isso porque Adam Smith considera essencial que; "todo imposto deve ser planejado de tal modo, que retire e conserve fora do bolso das pessoas o mínimo possível, além da soma que ele carreia para os cofres do Estado" ${ }^{3}$. Nesse cenário, o autor de Glasgow cita quatro possibilidades de o imposto onerar mais ao contribuinte do que o Estado consegue aproveitar em prol da sociedade: a cobrança do imposto exigir um número muito grande de funcionários que consumiriam parcela considerável dos valores arrecadados, além da probabilidade de suas gorjetas acarretarem taxa adicional ao povo; o desestímulo ao investimento em certos setores de negócios que poderiam ser fonte de sustento e emprego para parcela significativa da população; o confisco e outras penalidades que poderiam arruinar aqueles que tentassem sonegar o pagamento de impostos, pondo fim ao benefício que a arrecadação poderia ter auferido no emprego desses capitais; e, por fim, o fato de que a cobrança de impostos sujeita o povo a visitas constantes e inspeção de coletores, podendo expor o contribuinte a vexames e opressões desnecessárias.

Princípio tradicional no Ordenamento Jurídico Brasileiro, a capacidade contributiva foi afastada pelo regime autoritário de 1965, sendo restabelecida apenas com a CRFB/88, em seu art. $145, \S 1^{\circ}$ que reza:

Sempre que possível, os impostos terão caráter pessoal e serão graduados segundo a capacidade econômica do contribuinte, facultado à administração tributária, especialmente para conferir efetividade a esses objetivos, identificar, respeitados os

\footnotetext{
${ }^{1}$ SMITH, A. A riqueza das nações. v. 1. Trad. Alexandre Amaral Rodrigues. São Paulo: Martins Fontes, 2003.

${ }^{2}$ SMITH, A riqueza das nações: investigação sobre sua natureza e suas causas. v. 2. Trad. Luiz João Baraúna. São Paulo: Nova Cultura, 1996. p. 282.

${ }^{3}$ SMITH, op cit., p. 283.
} 
direitos individuais e nos termos da lei, o patrimônio, os rendimentos e as atividades econômicas do contribuinte ${ }^{4}$.

Aludido Princípio está diretamente relacionado aos Princípios da Igualdade e da Solidariedade, consubstanciando-se em um dos elementos fundamentais para garantia da justiça fiscal, como destaca Carrazza:

\begin{abstract}
Os impostos, quando ajustados à capacidade contributiva, permitem que os cidadãos cumpram, perante a comunidade, seus deveres de solidariedade política, econômica e social. Os que pagam esse tipo de exação devem contribuir para as despesas públicas não em razão daquilo que recebem do Estado, mas de suas potencialidades econômicas. Com isso, ajudam a remover os obstáculos de ordem econômica e social que limitam, de fato, a liberdade e igualdade dos menos afortunados 5 .
\end{abstract}

Ao discorrer sobre o Princípio da Isonomia ou Igualdade Tributária, Luciano Amaro, igualmente destaca essa interligação entre os princípios: "Hão de ser tratados, pois, com igualdade aqueles que tiverem igual capacidade contributiva, e com desigualdade aqueles que revelem riquezas diferentes e, portanto, diferentes capacidades de contribuir" ${ }^{6}$. Com o mesmo viés, mas voltado ao Princípio da Eficiência em matéria tributária, destaca-se o posicionamento de Martins, para o qual a "justiça da tributação e geração de desenvolvimento econômico e social", está atrelada a exata detecção dos limites da capacidade contributiva e das imposições e estímulos necessários para que a sociedade progrida ${ }^{7}$.

Em que pese a função da capacidade contributiva como limitador do poder Estatal e garantidor da justiça fiscal, há que se considerar a possibilidade de sua limitação por outros princípios, como os relativos às finalidades extrafiscais. Sobre a temática destacam-se os ensinamentos de Ávila:

A capacidade contributiva, por exemplo, é limite ao poder estatal, ao mesmo tempo em
que é limitada por outros princípios, como aqueles relativos a finalidades extrafiscais.
[...] Quando se faz referência às normas com finalidade fiscal (Fiskalzwecknorm) ou às
normas distributivas de encargo (Lastenausteilungsnorm), o poder de tributar é limitado
pelo princípio da capacidade contributiva. Sua finalidade, obtenção de receita, não é
idônea para estruturar sua interpretação. Mas a capacidade contributiva; enquanto
capacidade de contribuir com a comunidade mediante pagamento de tributo, inicia
somente acima do limite das necessidades para manutenção da vida. Por isso, fala-se em
zona de capacidade contributiva. Os outros direitos fundamentais, que são, direta ou

\footnotetext{
${ }^{4}$ BRASIL. Presidência da República. Casa Civil. Subchefia para Assuntos Jurídicos. Constituição da República Federativa do Brasil de 1988. Brasília: DOU, 5.10.1988. Disponível em:

<http://www.planalto.gov.br/ccivil_03/Constituicao/Constituicao.htm>. Acesso em 10 abr. 2020.

${ }^{5}$ CARRAZZA, Roque Antonio. Curso de Direito Constitucional Tributário. 30 ed. rev. ampl. e atual. São Paulo: Malheiros, 2015. p. 105.

${ }^{6}$ AMARO, Luciano. Direito Tributário Brasileiro. 21 ed. São Paulo: Saraiva, 2016. p. 160.

${ }^{7}$ MARTINS, I. G. da S. Princípio da eficiência em matéria tributária. In: MARTINS, I. G. da S. (Coord.). Princípio da eficiência em matéria tributária. São Paulo: RT, 2006. p. 31.
} 
indiretamente, influenciados pela tributação, possuem uma função específica: eles não podem ser violados no seu núcleo essencial. Nesse campo, a proibição de excesso exerce um importante papel ${ }^{8}$.

Esse posicionamento é fundamental para compreender a importância econômico-social da extrafiscalidade para a sociedade, inclusive frente aos interesses individuais inseridos no princípio da capacidade contributiva. Logo, o equilíbrio entre a aplicação dos supramencionados princípios transcende a noção individualista de tributação e eleva a discussão da justiça tributária a um patamar global, como chamam a atenção Murphy e Nagel:

A justiça tributária tem que ser inserida em um contexto global da justiça social e dos objetivos legítimos do governo. Sendo assim, não podemos afirmar como princípio fixo e imutável que as pessoas com a mesma renda ou nível de bem-estar pré-tributário têm que pagar os mesmos impostos ${ }^{9}$.

Não obstante, pondera-se que:

[...] quando o poder de tributar deve ser exercido de acordo com um interesse social ou econômico especifico, qualquer afastamento do direito prima-facie de tratamento isonômico de acordo com a capacidade contributiva do sujeito passivo deve ser fundamentado de tal forma que a promoção dos fins seja controlada pelos três aspectos do postulado da proporcionalidade (adequação, necessidade, proporcionalidade em sentido estrito). [...] (1) Adequação: A norma simplificadora deve servir de meio para promover a praticabilidade e o controle administrativo, inatingíveis de outro modo. (2) Necessidade: A praticabilidade e o controle administrativo não poderiam ser promovidos por meio de outras medidas menos restritivas ao princípio da capacidade contributiva. (3) Proporcionalidade em sentido estrito: O princípio da capacidade contributiva deve ser observado na maior parte dos casos, mesmo quando sua restrição é justificada por finalidades relacionadas à simplificação. Se a capacidade contributiva do sujeito passivo puder ser observada pelo Poder Legislativo, a utilização de presunções e ficções deve ser afastada ${ }^{10}$.

Assim sendo, embora exista certa discricionariedade para aplicação do Princípio da Capacidade Contributiva em relação aos tributos extrafiscais, ante a sua função econômica e social, é necessário respeitar determinados critérios, que justificam a mitigação do princípio que auxilia na manutenção da igualdade tributária. Necessário, portanto, averiguar sobre a extrafiscalidade dos tributos.

\section{A EXTRAFISCALIDADE DOS TRIBUTOS}

$\mathrm{O}$ tributo tem como objetivo primordial, desde a antiguidade, o financiamento do

\footnotetext{
${ }^{8}$ ÁVILA, Humberto. Sistema constitucional tributário. 5. ed. São Paulo: Saraiva, 2012. p. 126/140.

${ }^{9}$ MURPHY, Liam; NAGEL, Thomas. O mito da propriedade privada: os impostos e a justiça. Trad. Marcelo Brandão Cipolla. São Paulo: Martins Fontes, 2005, p. 54.

${ }^{10}$ ÁVILA, 2012, p. 352.
} 
Estado, o qual deve fomentar o bem-estar coletivo e a justiça social. No contexto arcaico, o tributo seria encarado, de certa maneira, como forma de sacrifício dos súditos; assim:

A atual idéia [sic] secular de bem comum a ser alcançado pela ação estatal viabilizada
pelos recursos do tributo guarda certa identidade com a noção transcendental de que o
cumprimento do sacrifício e a entrega ao templo do que era devido a Deus acarretariam
em bênçãos que, sobrenaturalmente, garantiriam a justiça e a equidade no seio do
povo.

Lembra-se que o próprio dízimo já desempenhava, consoante Corrêa ${ }^{12}$, características de extrafiscalidade, uma vez que financiava não apenas o culto, mas também era utilizado para assistência social. Todavia, em geral, o papel do tributo era meramente fiscal, com objetivo de prover o erário público dos recursos necessários para os gastos indispensáveis: defesa do exterior, segurança do interior, serviços de instrução, justiça e obras públicas; ou seja, serviam apenas para satisfação das necessidades públicas.

Abandonados os conceitos de regulação espontânea do mercado e considerando que a atividade financeira não pode ser mais aceita apenas como meio de obtenção de riquezas e custeio de despesas públicas; os instrumentos financeiros, especificamente, os tributários, passaram a ser utilizados para obtenção de resultados econômicos e políticos, tais como: reprimir a inflação, evitar desemprego e recessão, desaquecer a atividade econômica, proteção da indústria nacional, promover a redistribuição de renda nacional, nivelar fortunas, dentre outras funções.

Toda essa interferência no sistema financeiro e na economia demonstra que a tributação extrafiscal amplia a noção de justiça fiscal para além da capacidade contributiva, materializandose na adequação e ampliação da estrutura da fazenda pública ${ }^{13}$. Destarte, “[...] não se pode olvidar que a tributação é forma de intervenção no domínio econômico e que por meio dela o Estado pode ventilar políticas econômicas" ${ }^{14}$.

Como Princípio de legitimação da incidência tributária, a extrafiscalidade vem ganhando cada vez mais destaque, principalmente pela evolução do Estado Social, pois com a inclusão de direitos humanos de segunda e terceira geração, os Estados sentiram a necessidade de instituir tributos finalísticos para tornarem viáveis à efetivação desses direitos. Esses valores

\footnotetext{
${ }^{11}$ CORRÊA, C. D. Direito, religião e fiscalidade no antigo testamento. In: BALTHAZAR, U. C. (Org.). O tributo na história: da antiguidade à globalização. Florianópolis: Fundação Boiteux, 2006. p. 9-27. [p. 20].

${ }^{12}$ Op. Cit. 2006. p. 22.

${ }^{13}$ Neste sentido: AZEVEDO, Lyza Anzanello de. Análise Econômica da Tributação: A importância da arrecadação do ICMS para garantia dos direitos sociais. 1 ed. Rio de Janeiro: Multifoco, 2017.

${ }^{14}$ GOUVÊA, M. de F. A extrafiscalidade no direito tributário. Belo Horizonte: Del Rey, 2006. p. 11.
} 
aos quais se prestam os tributos não são elencados de maneira aleatória, mas estão expressamente previstos na CRFB/88, como o art. $1^{\circ}$ que trata dos valores do trabalho e da livre iniciativa, o art. $3^{\circ}$ que prevê como objetivos fundamentais da República a construção de sociedade livre, justa e solidária, a garantia do desenvolvimento nacional, a erradicação da pobreza e da marginalização, a redução das desigualdades sociais e regionais e a promoção do bem de todos.

No Capítulo que trata da Ordem Econômica e Financeira, também se encontram presentes valores importantes, com destaque para o art. 170 da CRFB/88 que enfatiza a valorização do trabalho humano e da livre iniciativa. Seus incisos podem ser divididos em dois grupos, a saber: os que definem os parâmetros para o desenvolvimento da nação (II, III e IV) e aqueles voltados para os objetivos a serem alcançados (I, V, VI, VII, VII, XIX).

No mesmo norte, cita-se o Capítulo da Ordem Social (art. 193 e ss. da CRFB/88), o qual determina objetivos primordiais ao desenvolvimento social do Estado como a promoção da seguridade social (arts. 194 e 195 da CRFB/88), da saúde (arts. 196 a 200 da CRFB/88), da previdência social (arts. 201 e 202 da CRFB/88), da assistência social (arts. 203 e 204 da CRFB/88), da educação da cultura e do desporto (arts. 205 a 219 da CRFB/88), dentre outros.

Esse arcabouço Constitucional coaduna com a criação do Estado Social, o qual primordialmente poderá ser realizado por meio de políticas públicas que utilizam a tributação como meio para atingir os fins e valores estabelecidos. Neste viés, a extrafiscalidade deve cumprir com seus objetivos constitucionais, como o desenvolvimento socioeconômico, concretizado no estímulo ao auxílio à acumulação do capital, à busca e manutenção do pleno emprego, à repartição de renda e riqueza; na geração de tecnologia; na preservação do meio ambiente; no desenvolvimento urbano e rural (reforma agrária) e no desenvolvimento sociocultural, representado pela proteção da família, pela promoção da seguridade social e pelo incentivo à cultura, à educação e ao desporto ${ }^{15}$.

O Estado, para atender essas competências institucionais a que é vinculado pela CRFB/88, necessita arrecadar recursos, sendo sua principal fonte de receitas a tributação. Assim, mediante as economias privadas, o governo consegue minimizar as carências públicas. Isso porque:

O sistema constitucional assinala para o tributo a função primordial de financiamento das atividades públicas, ao passo que restringe a exploração econômica por parte do

\footnotetext{
${ }^{15}$ Neste sentido, ver: GOUVÊA, Op. Cit. 2006.
} 
Estado e relega a papel secundário os demais instrumentos de captação de receitas públicas. $^{16}$

A esse Estado, cujas necessidades financeiras são preponderantemente financiadas por impostos ${ }^{17}$, a doutrina denominou como "Estado Fiscal", que nos dizeres de Nabais distingue-se do "Estado Tributário", o qual o doutrinador define como "[...] um Estado preponderantemente assente em termos financeiros, não em tributos unilaterais - impostos -, mas sim em tributos bilaterais - taxas, contribuições especiais etc." ${ }^{18}$. O "Estado Fiscal”, embora forneça ao Estado o instrumento necessário para prover os cofres públicos por meio da tributação, o priva da atividade econômica, fazendo com que ele atue como mero interventor na correção ou transformação do mercado quando da exploração do patrimônio público ou na realização de atividade empresarial.

O contexto fático demonstra que essa preferência pela tributação não é decisão meramente econômica, mas, sobretudo, de preferência Constitucional como expressa a teoria disseminada por Nabais relativa ao dever fundamental de pagar impostos. No tocante a esse dever fundamental de pagar impostos, é importante trazer à baila a lição de Correia Neto:

[...] o dever geral de pagar impostos - ou, grosso modo, tributos - significa também o comprometimento do indivíduo com a comunidade que o acolhe e a repartição dos custos de instalação, manutenção e aperfeiçoamento do Estado Social e Democrático de Direito. A obrigação tributária configura, nesse sentido, dever para com a própria comunidade, baseada nos valores de responsabilidade e de solidariedade, manifestados no imperativo de justa repartição dos gastos públicos. ${ }^{19}$

Especificamente sobre a reciprocidade entre os direitos fundamentais e os tributos, o referido autor ainda acrescenta:

Trata-se da interface positiva que se estabelece entre os tributos e os direitos fundamentais, na qual se enxergam as normas tributárias não apenas como limitadas pelos direitos fundamentais, mas também sua fonte de financiamento e, nessa medida, como condicionante de sua concretização ${ }^{20}$.

Após determinar que o pagamento de tributos seja dever fundamental, fica necessário

\footnotetext{
${ }^{16}$ CORREIA NETO, C. de B. O avesso do tributo. São Paulo: Almedina, 2014. p. 73.

17 "A referência a impostos em particular, e não a qualquer tributo em geral, explica-se porque o imposto como meio de financiamento geral independe de prestações estatais concretas, permite ao Estado a necessária mobilidade e independência no financiamento das tarefas públicas [...]. A ausência de bilateralidade cria certa independência nas escolhas (orçamentárias) do Estado, em relação aos contribuintes individualmente considerados [...]" (Ver Op. Cit. p. 73).

${ }^{18}$ NABAIS, J. C. O dever fundamental de pagar impostos: contributo para compreensão do Estado fiscal contemporâneo. Coimbra: Livraria Almedina, 1998. p. 187.

${ }^{19}$ CORREIA NETO, Op. Cit. 2014. p. 77.

${ }^{20}$ Idem, Ibidem.
} 
observar alguns quesitos, tais como a aptidão do tributo para transcender os meros efeitos arrecadatórios, a existência de efeitos extrafiscais predeterminados pela legislação e a relação entre a aptidão em arrecadar tributos e suas demais consequências e finalidades.

Quanto à aptidão dos tributos para irem além da mera finalidade arrecadatória, afirma Correia Neto $^{21}$ que não existe tributo neutro, pois mesmo os tributos puramente fiscais transferem riquezas entre classes ou produzem novas fontes de bem-estar social. Assim, todos os impostos acabam tendo alguma função social, econômica ou política. Entendimento igualmente sustentado por Carvalho:

Há tributos que se prestam, admiravelmente, para a introdução de expedientes extrafiscais. Outros, no entanto, inclinam-se mais ao setor da fiscalidade. Não existe, porém entidade tributária que se possa dizer pura, no sentido de realizar tão só a fiscalidade, ou, unicamente, a extrafiscalidade. Os dois objetivos convivem, harmônicos, na mesma figura impositiva, sendo apenas lícito verificar que, por vezes, um predomina sobre o outro. ${ }^{22}$

Necessário, aqui, explicar a fulcral diferença entre efeito e finalidade do tributo: afirmar que os tributos podem ter efeitos que ultrapassam o mero fim arrecadatório não é o mesmo que declarar que eles tenham sido propositalmente determinados para este objetivo. Essa diferença de caracterização foi apontada por Nabais, que divide a extrafiscalidade em dois grupos: a extrafiscalidade eminente (imprópria), a qual está presente em todos os tributos, tem caráter secundário ou acessório (efeitos econômicos e sociais) e não constitui característica fundamental; e a extrafiscalidade em sentido próprio ou estrito em que, neste caso, o objetivo principal do tributo é outro que não a arrecadação, estando presente nos impostos regulatórios e nos benefícios fiscais $^{23}$. Assim, o tributo tem por objetivo, para além de carrear aos cofres do Estado meios financeiros para satisfação das necessidades da coletividade ${ }^{24}$, ou seja, promover mais do que a mera captação de recursos; a efetiva realização dos valores constitucionais.

\section{ANÁlISE DA JURISPRUDÊNCIA NACIONAL SOBRE A CAPACIDADE CONTRIBUTIVA E A EXTRAFISCALIDADE}

$\mathrm{Na}$ teoria restou demonstrada a possibilidade de relativização do Princípio da Capacidade Contributiva ante a relevância da extrafiscalidade, agora se passa ao exame de como as Cortes Nacionais aplicam essa mitigação.

\footnotetext{
${ }^{21}$ CORREIA NETO, 2014.

${ }^{22}$ CARVALHO, P. de B. Direito tributário, linguagem e método. São Paulo: Noeses, 2008. p. 241.

${ }^{23}$ Neste sentido, ver: NABAIS, 1998.

${ }^{24}$ Assim, também, ver in MARTINS, S. P. Manual de direito tributário. 13. ed. São Paulo: Atlas, 2014. p. 80.
} 
Primeiramente, esclarece-se que não será necessariamente extrafiscal uma norma não amparada pela capacidade contributiva, porquanto podem ser editadas normas tributárias com finalidade fiscal e não compatíveis com o Princípio da Capacidade Contributiva, ou seja, não se estaria diante de uma norma tributária extrafiscal, mas de uma norma tributária fiscal inconstitucional $^{25}$. Ademais, há a possibilidade de normas extrafiscais respeitarem o critério da capacidade contributiva, concluindo-se, com isso, que o critério da aplicação da capacidade contributiva não é suficiente para determinar se uma norma tributária é ou não extrafiscal.

Em outro aspecto, a extrafiscalidade pode ser definida pela sua vinculação ou à arrecadação, fato gerador, ou à destinação do produto arrecadado, aspecto finalístico do tributo, voltado exatamente para realização dos fins, ou seja, dos direitos fundamentais garantidos pela Carta Magna.

Os fatos geradores são classificados no Código Tributário Nacional (CTN) conforme sua natureza econômica (patrimônio, renda, produção e circulação e comércio exterior) e; seu efeito extrafiscal é classificado conforme a diferenciação entre o contribuinte de direito ${ }^{26}$, o qual recolhe o tributo, e o contribuinte de fato, que arca com o ônus financeiro, ou seja, em tributos diretos, sem possibilidade de repasse para terceiros, como no caso do Imposto de Renda da Pessoa Física (IRPF) ${ }^{27}$ e no Imposto Predial e Territorial Urbano (IPTU), e indiretos, com possibilidade de repasse do ônus para terceiros como exemplifica o Imposto sobre a Circulação de Mercadorias (ICMS). Isso porque os tributos indiretos irão onerar o preço, interferindo na elasticidade-preço ${ }^{28}$ dos bens repassados aos consumidores, enquanto os tributos diretos oneram a renda, refletindo na elasticidade-renda ${ }^{29}$ de bens. A tributação sobre a renda, segundo os pressupostos keynesianos, seria o modo de tributação menos oneroso para economia - se comparado à tributação indireta, além de ser excelente ferramenta para redução das desigualdades sociais. A CRFB/88 prevê três tributos cujo fato gerador é a renda: o Imposto de Renda (art. 153, II, da CRFB/88); a Contribuição Social sobre o Lucro Líquido (CSLL) (art. 195,

\footnotetext{
${ }^{25}$ BOMFIM, Diego. Proposta teórica de identificação das normas tributárias extrafiscais. In: Cristiano Carvalho (Coord.). Direito Tributário Atual. 1 ed. Rio de Janeiro: Elsevier, 2015.

${ }^{26}$ A classificação entre contribuinte de direito e de fato é apenas econômica e financeira, não sendo considerada jurídica, uma vez que contribuinte de direito é uma redundância, e contribuinte de fato é juridicamente inexistente. ${ }^{27}$ Destaca-se, aqui, a inclusão apenas do Imposto de Renda da Pessoa Física (IRPF), uma vez que o Imposto de Renda da Pessoa Jurídica (IRPJ) é incluído no valor da mercadoria e acaba sendo pago pelo consumidor.

28 "Relação entre a variação relativa na quantidade procurada ou ofertada de um bem e uma variação relativa de seu preço" In SANDRONI, P. (Org.). Novíssimo dicionário de economia. 1. ed. São Paulo: Best Seller, 1999. p. 200.

29 "Medida da variação na quantidade demandada de um bem quando a renda do consumidor é alterada, mantendose constantes todos os outros fatores que influenciam a demanda. Para obter o coeficiente de elasticidade-renda da de- manda, divide-se a variação percentual da quantidade demandada pela variação percentual na renda do consumidor" (Ibidem, p. 200).
} 
II, da CRFB/88); e o Imposto sobre Grandes Fortunas (IGF) (art. 153, VII, da CRFB/88). O Imposto de Renda tem sua extrafiscalidade explicita na capacidade contributiva, a qual permite tributar mais quem aufere maior renda, gerando redistribuição de riquezas, por fazer com que os contribuintes mais ricos arquem proporcionalmente mais com as despesas públicas.

Já a Contribuição Social sobre o Lucro Líquido possui contribuição seletiva em razão da atividade econômica desempenhada pela empresa e a intensidade de mão de obra empregada. Desse modo, seu efeito extrafiscal é observado na seletividade pela mão de obra, pois quanto menos tributos a empresa pagar, mais estímulos terá para aumentar a oferta de emprego.

Ainda entre os tributos que afetam a elasticidade-renda de bens, estão aqueles que incidem sobre o patrimônio como: o Imposto Territorial Rural (ITR) conforme Lei $n^{\circ}$ 9.393/96; o IPTU (art. 156, I, da CRFB/88), o Imposto sobre Veículos Automotores (IPVA) previsto no art. 155, III, da CRFB/88, o Imposto sobre Transmissão Causa Mortis e Doação de Quaisquer Bens ou Direitos (ITCD) insculpido no art. 155, I, da CRFB/88 e o Imposto sobre a Transmissão de Bens Imóveis (ITBI) segundo o art. 155, I, da CRFB/88. O ITR tem caráter extrafiscal claro como instrumento de política agrária. O IPTU, além de ser instrumento para o desenvolvimento urbano, é notadamente extrafiscal por motivar o cumprimento da função social da propriedade, redistribuir riquezas (progressividade na cobrança em razão do valor do imóvel) e estimular ou desestimular a urbanização em determinadas áreas.

Com relação ao IPVA, a extrafiscalidade pode ser externalizada de dois modos: com a manipulação das alíquotas para onerar ou desonerar a aquisição de determinados modelos de veículos; de modo progressivo incidindo mais amplamente nos veículos mais caros, ou mesmo em razão do tipo e utilização, conforme dispõe o art. $155, \S 6^{\circ}$, da $\mathrm{CRFB} / 88$ : "poderá ter alíquotas diferenciadas em função do tipo e utilização".

Os efeitos extrafiscais do ITCD e do ITBI ainda são limitados e em ambos estão ligados à progressividade do tributo que poderia ser ampliada, atingindo, por exemplo, as grandes fortunas que hoje não são devidamente afetadas por estes tributos.

Campo vertiginoso é o dos tributos incidentes sobre produção, circulação e consumo. Estes são considerados tributos fiscais por excelência, porquanto são os fatos geradores que mais captam receitas para os cofres públicos. Dentre eles citam-se como principais: o Imposto sobre a Produção Industrial (IPI) descrito no art. 153, IV, da CRFB/88; o Imposto sobre a Circulação de Mercadorias e Serviços (ICMS) descrito no art. 155, II, da CRFB/88; o Imposto sobre Serviços de Qualquer Natureza (ISS) conforme o art. 156, III, da CRFB/88; o Programa de Integração 
Social (PIS) previsto na Lei Complementar n 7, de 1970; a Contribuição para o Financiamento da Seguridade Social (COFINS) próprio da Lei Complementar n 70, de 1991, a Contribuição de Intervenção no Domínio Econômico (CIDE) ${ }^{30}$ sobre os combustíveis segundo a Lei $n^{\circ}$ $10.336 / 2001$ e a CIDE royalties própria da Lei $\mathrm{n}^{\circ} 10.168 / 2000$. No que concerne a extrafiscalidade desses tributos, discorre Gouvêa:

\begin{abstract}
Em linhas gerais, os efeitos extrafiscais desses tributos são aqueles já apreciados: alteração de preços relativos, estímulo ou desestímulos a condutas etc. Em termos específicos, extraem-se efeitos extrafiscais da tributação sobre o consumo mediante a implementação particular da não-cumulatividade, da seletividade, da incidência nas exportações e da flexibilidade diante dos princípios da legalidade e da não surpresa em cada um dos tributos. ${ }^{31}$
\end{abstract}

A não cumulatividade dos tributos é benéfica pela sua neutralidade, vez que tributos cumulativos distorcem os preços, oneram exportações e são responsáveis pela verticalização das empresas $^{32}$. Por isso, a importância da não cumulatividade do IPI e do ICMS prevista Constitucionalmente. O mesmo não se pode falar do ISS, que não tem, na CRFB/88, previsão expressa para não cumulatividade, ficando a critério do legislador municipal ordinário tratar do ISS de forma não cumulativa.

No que concerne ao PIS e à COFINS, o legislador tem gradualmente inserido a não cumulatividade por meio, respectivamente, da Lei $n^{\circ} 10.637 / 2002$ e da Lei $n^{\circ} 10.833 / 2003^{33}$, já no caso das Contribuições de Intervenção no Domínio Econômico (CIDE dos combustíveis e CIDE dos royalties), incidem, normalmente, em apenas uma fase do processo produtivo, o que inibe os malefícios da cumulatividade. A não cumulatividade desses tributos também é fator relevante como incentivo às exportações, por reduzirem o valor do produto exportado e torná-lo mais competitivo internacionalmente - inclusive IPI, ICMS e ISS não incidem nas exportações por imposição Constitucional.

A extrafiscalidade também pode ser decorrente da seletividade dos produtos. O IPI, por exemplo, é considerado um tributo regulatório, diante da sua seletividade obrigatória, já no caso do ICMS a seletividade em função da essencialidade das mercadorias e dos serviços é facultativa. Contudo, no caso do ICMS os interesses fiscais podem levar a elevadas cargas

\footnotetext{
${ }^{30}$ Contribuições de Intervenção no Domínio Econômico (CIDE).

${ }^{31}$ GOUVÊA, 2006. p. 163.

32 “Atuação de uma empresa em mais de um estágio do processo produtivo, o que frequentemente ocorre por meio da fusão de várias empresas que atuam em estágios diferentes. O mais abrangente tipo de verticalização ou integração vertical é o da empresa que controla desde a produção de matérias-primas até a confecção final do produto" Ver In: SANDRONI, 1999. p. 634.

${ }^{33}$ Com fundamento no art. $195, \S 12$, da CRFB/88.
} 
tributárias de produtos essenciais, como o caso das telecomunicações. Diante de toda essa liberalidade e visando evitar excessos, a CRFB/88 estabeleceu limitações a esta faculdade, sobre as quais discorre Machado:

\begin{abstract}
A Constituição Federal de 1988 estabeleceu que o ICMS poderá ser seletivo em função da essencialidade das mercadorias e serviços (art. $155, \S 2^{\circ}$, III), facultando, assim, seu uso com função extrafiscal. Todavia, consciente dos problemas que daí podem decorrer, cuidou de estabelecer fortes limitações a essa faculdade, atribuindo ao Senado Federal competência para estabelecer as alíquotas aplicáveis às operações e prestações, interestaduais e de exportação, e a este facultando o estabelecimento de alíquotas mínimas e máximas nas operações internas (art. $155, \S 2^{\circ}$, IV e V). ${ }^{34}$
\end{abstract}

Neste norte, ainda pode-se citar a extrafiscalidade do Imposto sobre Operações Financeiras (IOF) que por não estar vinculado ao princípio da anterioridade é utilizado como instrumento anti-inflacionário, sendo ajustado aos objetivos da política monetária, bem como o Imposto de Importação e o Imposto de Exportação que não obtêm grandes resultados em termos de arrecadação, mas são eficazes instrumentos de política econômica.

A extrafiscalidade dos tributos conforme seus fatos geradores é apenas uma das dimensões a se levada em consideração, pois, referido instituto, pode estar também relacionado ao destino do produto arrecadado pelos tributos, porém, neste sentido, limitam-se as contribuições, por serem tributos finalísticos por excelência. A aplicação dessas noções de extrafiscalidade dos tributos pode ser verificada nas decisões proferidas pelos Tribunais Pátrios. Ao analisar ação ajuizada por empresa objetivando não ser compelida ao recolhimento do $\mathrm{RAT}^{35}$ com a aplicação do Fator Acidentário de Prevenção (FAP), introduzido pela Lei no 10.666/2003, diante da ilegalidade da metodologia do FAP, o qual afrontaria os princípios da legalidade e segurança jurídica, o Tribunal Regional Federal da Terceira Região decidiu:

TRIBUTÁRIO. MANDADO DE SEGURANÇA. MAJORAÇÃO DA ALÍQUOTA DE RECOLHIMENTO DO RAT/SAT. EMPREGO DO FAP. ART. 10 DA LEI N ${ }^{\circ}$ 10.666/2003, ART. 202-A DO DECRETO No 3.048/1999, E RESOLUÇÕES N $N^{\circ} 1.308$ E $1.309 / 2009$ DO CNPS. AUSÊNCIA DE ILEGALIDADE E DE INCONSTITUCIONALIDADE.

1. A Lei ${ }^{\circ} 10.666 / 2003$, artigo 10, introduziu na sistemática de cálculo da contribuição ao SAT o Fator Acidentário de Prevenção (FAP), como um multiplicador de alíquota que irá permitir que, conforme a esfera de atividade econômica, as empresas que melhor preservarem a saúde e a segurança de seus trabalhadores tenham descontos na referida alíquota de contribuição. Ou não, pois o FAP é um índice que pode reduzir à metade, ou duplicar, a alíquota de contribuição de $1 \%, 2 \%$ ou $3 \%$, paga pelas empresas, com base em indicador de sinistralidade, vale dizer, de potencialidade de infortunística no ambiente de trabalho. O FAP oscilará de acordo com o histórico de doenças

\footnotetext{
${ }^{34}$ MACHADO, H. de B. Curso de Direito Tributário. 33. ed. rev., atual. e ampl. São Paulo: Malheiros, 2012. p. 372.

${ }^{35}$ Nova denominação para o SAT (Seguro Acidente do Trabalho).
} 
ocupacionais e acidentes do trabalho por empresa e incentivará aqueles que investem na prevenção de agravos da saúde do trabalhador. 2. Não há que se falar, especificamente, na aplicação de um direito sancionador, o que invocaria, se o caso, o artigo $2^{\circ}$ da Lei ${ }^{\circ}$ 9.784/99; deve-se enxergar a classificação das empresas face o FAP não como "pena" em sentido estrito, mas como mecanismo de fomento contra a infortunística e amparado na extrafiscalidade que pode permear essa contribuição SAT na medida em que a finalidade extrafiscal da norma tributária passa a ser um arranjo institucional legítimo na formulação e viabilidade de uma política pública que busca salvaguardar a saúde dos trabalhadores e premiar as empresas que conseguem diminuir os riscos da atividade econômica a que se dedicam. 3. Ausência de violação do princípio da legalidade: o decreto não inovou em relação às Leis $n^{\circ}$ 8.212/91 e 10.666/2003, apenas explicitou o que tais normas determinam. O STF, por seu plenário, no RE $n^{\circ} 343.466 / \mathrm{SC}$ (RTJ, 185/723), entendeu pela constitucionalidade da regulamentação do então SAT (hoje RAT) através de ato do Poder Executivo, de modo que o mesmo princípio é aplicável ao FAP. 4. Inocorrência de inconstitucionalidade: a contribuição permanece calculada pelo grau de risco da atividade preponderante da empresa, e não de cada estabelecimento, sem ofensa ao princípio da igualdade tributária (art. 150, II, CF) e a capacidade contributiva, já que a mesma regra é aplicada a todos os contribuintes, sendo que a variação da expressão pecuniária da exação dependerá das condições particulares do nível de sinistralidade de cada um deles. 5. Recurso da autora improvido, apelo da União Federal e remessa oficial providos $^{36}$. (Grifo nosso).

Destarte, quanto ao caráter extrafiscal do tributo em questão, explica o próprio magistrado aludindo que:

Até o advento dessa lei, e da sua regulamentação, a tarifação da contribuição para custeio do SAT (artigo 22 do PCPS) era coletiva, variando apenas as alíquotas conforme o exercício da atividade do empregador. O artigo 10 da Lei $\mathrm{n}^{\circ}$ 10.666/2003 trouxe saudável novidade: a possibilidade de estabelecer a tarifação individual das empresas, flexibilizando o valor das alíquotas. Empregadores que tenham feito um bom trabalho nas melhorias dos postos de trabalho e apresentado menores índices de acidentalidade, podem ser aquinhoados com a diminuição da alíquota, ao mesmo tempo em que deve aumentar a cobrança daquelas empresas que tenham apresentado índices de acidentalidade superiores à média de seu setor econômico, revelando descaso para com um valor básico de nossa democracia: o prestígio do trabalho como valor social. [...] A diferenciação na verdade é um critério de justiça, pois nada ampara que continue a sinistralidade nas relações laborais; no Brasil as estatísticas indicam que a cada duas horas ocorrem três mortes, e a cada minuto acontecem três acidentes, envolvendo os trabalhadores do mercado formal. No ano de 2003, quando aprovado o FAP, a ausência de segurança nos ambientes de trabalho no Brasil gerou um custo de cerca de $\mathrm{R} \$ 32,8$ bilhões para o País.

Na hipótese, restou demonstrado que o tributo tem como função o fomento de práticas mais seguras de trabalho com objetivo de reduzir o número de acidentes laborais, bem como, não seria ofensa ao Princípio da Capacidade Contributiva, por ser a regra de flexibilização das alíquotas utilizada para todos os contribuintes. Especificamente sobre o tema colhe-se da jurisprudência catarinense, ao tratar da alíquota aplicada ao ICMS referente à utilização de energia elétrica, o que segue:

\footnotetext{
${ }^{36}$ TRF $3^{a}$ Região. Apelação/Reexame Necessário n ${ }^{\circ}$ 0002124-18.2010.4.03.6100, Rel. Des. Federal Johonsom Di Salvo, j. em 07-08-2012, e-DJF3 Judicial 1 DATA:14-08-2012. Acesso em 14 abr. 2020.
} 


\begin{abstract}
APELAÇÃO CÍVEL - TRIBUTÁRIO - MANDADO DE SEGURANÇA - ICMS SOBRE ENERGIA ELÉTRICA E SERVIÇOS DE TELECOMUNICAÇÕES ALÍQUOTA DE 25\% (VINTE E CINCO POR CENTO) - INEXISTÊNCIA DE VIOLAÇÃO AO PRINCÍPIO CONSTITUCIONAL DA SELETIVIDADE SENTENÇA MANTIDA - RECURSO CONHECIDO E DESPROVIDO. "Não obstante sustente, grande parte da doutrina, a inconstitucionalidade de leis estaduais que estabelecem alíquotas máximas (até 25\%) para o ICMS incidente sobre operações com energia elétrica, sob o fundamento de que se trata de uma mercadoria tão essencial quanto qualquer outra de primeira necessidade, a incidência de alíquota mais elevada sobre as operações com energia elétrica não viola o princípio constitucional da seletividade fundado na essencialidade da mercadoria (art. 155 , § $2^{\circ}$, inciso III, da $\mathrm{CF} / 88$ ), sobretudo porque não tem apenas o objetivo de abastecer os cofres públicos com os recursos financeiros necessários à manutenção das atividades estatais (fiscalidade), mas também o de evitar o consumo abusivo e o desperdício que, se não for controlado pelo Poder Público, poderá levar ao racionamento forçado da energia elétrica, comprometendo, indubitavelmente, o crescimento do País e, via de consequência, toda a sociedade brasileira." (TJSC - Apelação Cível n. 2007.030369-1, rel. Des. Jaime Ramos, j. 12.2.2010), ademais do que se trata de medida respaldada pelos princípios tributários da capacidade contributiva e da isonomia. (TJSC, Apelação Cível n. 0312136-82.2016.8.24.0023, da Capital, rel. Des. João Henrique Blasi, j. 2609-2017) ${ }^{37}$. (Grifo nosso).
\end{abstract}

É plausível extrair-se do "corpo do Acórdão" a lição que segue quanto ao uso extrafiscal do tributo:

Isso porque, cada vez mais, a tributação se afasta da sua ordinária finalidade arrecadatória, voltando-se à consecução de desígnios outros, atinentes à ordenação da economia e das relações sociais, em verdadeira função extrafiscal. Nos dizeres de Geraldo Ataliba, 'consiste a extrafiscalidade no uso de instrumentos tributários para obtenção de finalidades não arrecadatórias, mas estimulantes, indutoras ou coibidoras de comportamentos, tendo em vista outros fins, a realização de outros valores constitucionalmente consagrados' (ATALIBA, Geraldo. IPTU Progressividade. Revista de Direito Público (RDP) 93/233). Assim é que, mesmo com relação a serviços potencialmente reputados 'essenciais' à sociedade, como seria o caso da energia elétrica, e até mesmo das comunicações, será possível a imputação de alíquotas tributárias mais gravosas, como forma de regulação das relações sociais no tocante a esses serviços. Nesse sentido, Eduardo Sabbag também assenta, em outra passagem de sua obra, o entendimento de que: [...] também podem hospedar a tributação mais expressiva aqueles impostos que incidem sobre a energia elétrica e combustíveis (art. 155, § $3^{\circ}, \mathrm{CF}$ ), a saber, o II, o IE e o ICMS, visando a coibir o consumo. Ante o exposto, diz-se que as situações de ressalvas para os impostos em epígrafe, no bojo de um fiscalismo mais enérgico, na expressão de Baleeiro, são justificadas pelo fato de que tais gravames, deixando de cumprir seu precípuo desiderato fiscal, abrem-se como elemento de controle, na via da extrafiscalidade (Sabbag, Eduardo. Manual de direito tributário. 6. ed. São Paulo: Saraiva, 2014. p. 271) "Em suma, portanto, não há óbice à eventual mitigação da seletividade, ou mesmo da capacidade contributiva, pela extrafiscalidade." Valendo-se da discricionariedade que lhe é atribuída pelo constituinte, em verdadeiro juízo de conveniência e oportunidade, poderá, sim, o legislador estadual estipular alíquotas mais severas sobre algumas atividades, desde que o faça 'a partir de critérios racionais, lógicos e impessoais estabelecidos de modo legítimo em norma legal, a

\footnotetext{
${ }^{37}$ TJSC, Apelação Cível n ${ }^{\circ}$. 0307715-15.2017.8.24.0023, da Capital, rel. Des. Cid Goulart, Segunda Câmara de Direito Público, j. 03-04-2018. Acesso em 14 abr. 2020.
} 
implementar objetivos estatais nitidamente qualificados pela nota da extrafiscalidade" (STF, AI 142.348-1, Rel. Min. Celso de Mello).

Novamente, o que se vê é a relativização do Princípio da Capacidade Contributiva com o fim de evitar o desperdício da energia elétrica, bem extremamente precioso a toda sociedade.

Terreno mais vertiginoso é o da utilização do papel extrafiscal do IPTU, o qual pode gerar conflito interno entre a previsão abstrata da norma e a adequação aos fatos concretos, como exemplifica Ricardo Lodi:

\begin{abstract}
Exemplo desse conflito se dará na legislação do IPTU progressivo, que venha a determinar uma diferenciação de alíquotas em razão da localização do imóvel (art. 156, $\S 1^{\circ}$, da $\mathrm{CF}$, com redação dada pela $\mathrm{EC} \mathrm{n}^{\circ} 29 / 00$ ). Se tal diferenciação se traduzir em uma alíquota majorada para os bairros mais nobres, a aplicação desta alíquota aos imóveis de baixo valor, ainda que localizados nesses bairros, revelar-se-á desastrosa à capacidade contributiva. A solução desse conflito, nesse exemplo, se daria pelo afastamento da progressividade ${ }^{38}$.
\end{abstract}

Em que pese o exposto, entretanto, na jurisprudência o que se observa é a possibilidade de diferenciação da alíquota do aludido imposto conforme local e utilização do imóvel, distinção que, conforme os juristas catarinenses, não tem por base a progressividade do imposto, mas sua seletividade. É o que se vê:

APELAÇÃO CÍVEL. AÇÃO ORDINÁRIA DE REVISÃO DE ALÍQUOTA C/C. DECLARATÓRIA DE INEXIGIBILIDADE E REPETIÇÃO DE INDÉBITO. IPTUIMPOSTO PREDIAL E TERRITORIAL URBANO. SENTENÇA DE PROCEDÊNCIA. INSURGÊNCIA INTERPOSTA PELO MUNICÍPIO. ALEGAÇÃO DE QUE A ALÍQUOTA DIFERENCIADA NÃO DECORRE DE PROGRESSIVIDADE DO IMPOSTO, MAS, SIM, DA SELETIVIDADE. ARGUMENTAÇÃO PROFÍCUA. APLICAÇÃO DO PERCENTUAL DE ACORDO COM A LOCALIZAÇÃO E UTILIZAÇÃO DO IMÓVEL. LEGALIDADE. PRECEDENTES. INVERSÃO DOS ÔNUS SUCUMBENCIAIS. SENTENÇA REFORMADA. "[...] 'Com base no permissivo inscrito no art. 156, § $1^{\circ}$, inc. II, da Constituição Federal, com a redação dada pela Emenda Constitucional n. 29/2000, a destinação e o uso do imóvel podem ser utilizados como balizadores para a fixação das alíquotas do IPTU, desde que aplicados como forma de promover e orientar o adequado desenvolvimento urbano. Trata-se de viés extrafiscal da cobrança do IPTU, admitido pela Constituição. Assim, o legislador municipal, ao escolher a alíquota diferenciada para imóveis desprovidos de muro frontal e passeio público, em confronto com a legislação específica local, não atribui à exação cunho punitivo, mas sim prestigia o aludido mandamento constitucional' (Apelação Cível n. 2012.032598-5, de Joinville, rel. Des. Luiz Cézar Medeiros, j. em 08/05/2013)". (TJSC, Apelação Cível n ${ }^{\circ}$ 2012.032445-7, de Joinville, rel. Des. Carlos Adilson Silva, j. 28/04/2015). RECURSO CONHECIDO E PROVIDO ${ }^{39}$.

\footnotetext{
${ }^{38}$ RIBEIRO, Ricardo Lodi. Temas de Direito Constitucional Tributário. Rio de Janeiro: Lumen Juris, 2009. p. 222223.

${ }^{39}$ TJSC, Apelação n ${ }^{\circ}$ 0003670-40.2010.8.24.0038, de Joinville, rel. Des. Luiz Fernando Boller, Primeira Câmara de Direito Público, j. 23-08-2016. Acesso em 14 abr. 2020.
} 
Na hipótese, a particularização é claramente definida no voto segundo se observa:

Logo, o percentual de $2 \%$ (dois por cento) adotado pelo ente tributante com fulcro no aludido art. $2^{\circ}$, inc. II, da Lei Municipal $\mathrm{n}^{\circ} 2.020 / 84$, não decorre de alíquota progressiva no tempo - o que ocorreria, por exemplo, caso fosse aplicado o respectivo inc. V -, mas, sim, de critério seletivo de instituição do IPTU diante da ausência de muro frontal e de passeio público, bem como da localização e da disposição urbanística do imóvel, o que vai ao encontro do disposto no art. $156, \S 1^{\circ}$, inc. II, da Constituição Federal $[\ldots]$

Como ficou evidenciada nas decisões analisadas, essa mitigação da capacidade contributiva em detrimento do uso parafiscal do tributo no Território Nacional não pode ser desmedida bastando a simples alusão de um objeto extrafiscal para afastar a aplicação da capacidade contributiva. Verificada a contradição entre esses valores, a mesma deve ser resolvida pela ponderação de interesses e, principalmente, com a aplicação do Princípio da Razoabilidade como ensina Ricardo Lodi Ribeiro:

[...] como é quase consenso na moderna doutrina, não se pode afastar a aplicação da capacidade contributiva diante de um mero objetivo extrafiscal. É preciso, ao contrário, que o objetivo extrafiscal seja razoável, e que prevaleça diante de um juízo de ponderação de valores entre a igualdade e a capacidade contributiva, a fim de que não sejam criados privilégios odiosos sob o pano da extrafiscalidade ${ }^{40}$.

Portanto, mostra-se possível, na prática, a relativização do Princípio da Capacidade Contributiva em prol dos benefícios sociais da extrafiscalidade, desde que haja ponderação adequada entre os valores, com justificada fundamentação. Nesse sentido, a tributação deve ser progressista assegurando a democracia econômica, a produção, repartição, circulação e consumo das riquezas nacionais; fomentando a adequada ação Estatal sem, contudo, implicar em políticas econômico-tributárias distanciadas dos princípios constitucionalizados. Destarte, para além de alimentar os cofres públicos, a tributação deve ser instrumental político-econômico que permita a ação econômica continua e benfazeja em sociedade. A capacidade contributiva e o uso extrafiscal do tributo devem ser ponderados para a construção de uma sociedade equilibrada e promissora tal qual já se defendeu segundo o Princípio da Eficiência Econômico-Social (PEES) ${ }^{41}$. Ainda cabe referir, por último, ao uso da extrafiscalidade que não se justifica se incompatível com a capacidade contributiva do agente. Não por outro motivo que assola o Brasil, desde dia 21

\footnotetext{
${ }^{40}$ RIBEIRO, 2009. p. 224.

${ }^{41}$ GONÇALVES, Everton das Neves e STELZER, Joana. Principle of Social and Economic Efficiency (PSEE) at the Brazilians Law: the normative and judicial decision taking. In Sequencia: Estudos Jurídicos e Politicos, (S. I.), v. 35, n. 68, pp. 261-290, Jun. 2014. ISSN 2177-7055. Doi: http://dx.doi.org/10.5007/2177-7055.2013v35n68p261. Disponível em: https://periodicos.ufsc.br/index.php/sequencia/article/view/2177-7055.2013v35n68p261/26955. Acesso em: 14 abr. 2020.
} 
de maio de 2018, o movimento de paralização dos caminhoneiros em todo o Território Nacional. A reivindicação maior, para além de outras, é a extinção da CIDE sobre o óleo diesel e do PIS/COFINS segundo alegado impedimento, por parte do Estado, do exercício da atividade econômica em vista dos altos e constantemente majorados preços dos combustíveis, diga-se, praticados segundo níveis internacionais, pela Petrobrás. A esse fato, dia 27 de maio de 2018 , acenou o Governo Federal para o atendimento das referidas reivindicações demonstrando-se que a ponderação de interesses, na área tributária é tema sensível que interfere enormemente na economia nacional seja para dinamizar a ação estatal via orçamento público, seja para viabilizar a atividade econômica dos cidadãos nas mais variadas áreas da economia. Há, portanto, que se ter a adequada ponderação de princípios para discernir entre as melhores políticas econômicotributárias que permitam, para além do necessário fortalecimento do fluxo de caixa governamental, o desiderato do incentivo para a imprescindível ação econômica do agente particular, contribuinte, que, afinal de contas, gera a riqueza nacional.

\section{CONCLUSÃO}

Como se buscou confirmar nesse estudo a mitigação do Princípio da Capacidade Contributiva frente à extrafiscalidade dos tributos é de extrema importância para garantia de uma justiça fiscal universal, que não se preocupe apenas com a garantia dos direitos individuais, mas com os interesses de toda sociedade no cenário normativo Constitucional e infraconstitucional bem como jurisdicional Pátrio. Contudo, restou comprovado que mencionada relativização de valores não poderá ser realizada sem a devida ponderação e fundamentação, observados os três aspectos do postulado da proporcionalidade: adequação, necessidade e proporcionalidade em sentido estrito.

Com efeito, evidente que essa ponderação não pode representar um desrespeito à capacidade contributiva, Princípio tão caro à sociedade brasileira e recolocado no Ordenamento Jurídico Nacional a partir do trabalho da Constituinte de 1988.

Constatou-se, ainda, com o exame jurisprudencial, que esses parâmetros estão sendo concretizados na prática com a devida pertinência da mitigação da capacidade contributiva com o papel extrafiscal dos tributos conforme o estudo de cada caso concreto.

O Sistema Tributário Nacional deve ser inclusor das diversas categorias econômicas nacionais zelando pela continuidade da ação e da democracia econômica evitando, em nome do inexorável ajuste de caixa governamental a expropriação econômica dos particulares segundo 
percentuais tarifários que, para além da justa cobrança tributária, levem à inoperatividade do Sistema Econômico. A extrafiscalidade, por outro lado, deve garantir a continuidade de dada política econômica segundo a necessária ideologia econômica constitucionalmente adotada. É dever, pois, do Estado, ser sensível e perceber os anseios da coletividade nacional para que se viabilizando a atividade econômica nacional, não se exproprie a riqueza particular em vista de inexorável ajuste de caixa orçamentário. A capacidade contributiva deve ser observada e a extrafiscalidade deve ser instrumental de justiça econômico-política para a inclusão social segundo o Princípio da Eficiência Econômico-Social (PEES).

\section{REFERENNCIAS}

AMARO, Luciano. Direito Tributário Brasileiro. 21 ed. São Paulo: Saraiva, 2016.

ÁVILA, Humberto. Sistema constitucional tributário. 5. ed. São Paulo: Saraiva, 2012.

AZEVEDO, Lyza Anzanello de. Análise Econômica da Tributação: A importância da arrecadação do ICMS para garantia dos direitos sociais. 1 ed. Rio de Janeiro: Multifoco, 2017.

BOMFIM, Diego. Proposta teórica de identificação das normas tributárias extrafiscais. In: Cristiano Carvalho (Coord.). Direito Tributário Atual. 1 ed. Rio de Janeiro: Elsevier, 2015.

BRASIL. Presidência da República. Casa Civil. Subchefia para Assuntos Jurídicos. Constituição da República Federativa do Brasil de 1988. Brasília: DOU, 5.10.1988. Disponível em: http://www.planalto.gov.br/ccivil_03/Constituicao/Constituicao.htm. Acesso em 14 abr. 2020.

CARRAZZA, Roque Antonio. Curso de Direito Constitucional Tributário. 30 ed. rev. ampl. e atual. São Paulo: Malheiros, 2015.

CARVALHO, P. de B. Direito tributário, linguagem e método. São Paulo: Noeses, 2008.

CORRÊA, C. D. Direito, religião e fiscalidade no antigo testamento. In: BALTHAZAR, U. C. (Org.). O tributo na história: da antiguidade à globalização. Florianópolis: Fundação Boiteux, 2006.

CORREIA NETO, C. de B. O avesso do tributo. São Paulo: Almedina, 2014.

GONÇALVES, Everton das Neves e STELZER, Joana. Principle of Social and Economic Efficiency (PSEE) at the Brazilians Law: the normative and judicial decision taking. In Sequencia: Estudos Jurídicos e Políticos, (S. I.), v. 35, n. 68, pp. 261-290, Jun. 2014. ISSN 2177-7055. Doi: http://dx.doi.org/10.5007/2177-7055.2013v35n68p261 Disponível em: https://periodicos.ufsc.br/index.php/sequencia/article/view/2177-7055.2013v35n68p261/26955. Acesso em: 14 abr. 2020.

GOUVÊA, M. de F. A extrafiscalidade no direito tributário. Belo Horizonte: Del Rey, 2006. MACHADO, H. de B. Curso de direito tributário. 33. ed. rev., atual. e ampl. São Paulo: Malheiros, 2012.

MARTINS, S. P. Manual de direito tributário. 13. ed. São Paulo: Atlas, 2014. 
MARTINS, I. G. da S. Princípio da eficiência em matéria tributária. In: MARTINS, I. G. da S. (Coord.). Princípio da eficiência em matéria tributária. São Paulo: RT, 2006.

MURPHY, Liam; NAGEL, Thomas. O mito da propriedade privada: os impostos e a justiça. Trad. Marcelo Brandão Cipolla. São Paulo: Martins Fontes, 2005.

NABAIS, J. C. O dever fundamental de pagar impostos: contributo para compreensão do Estado fiscal contemporâneo. Coimbra: Livraria Almedina, 1998.

RIBEIRO, Ricardo Lodi. Temas de Direito Constitucional Tributário. Rio de Janeiro: Lúmen Juris, 2009.

SANDRONI, P. (Org.). Novíssimo dicionário de economia. 1. ed. São Paulo: Best Seller, 1999.

SMITH, A. A riqueza das nações. v. 1. Trad. Alexandre Amaral Rodrigues. São Paulo: Martins Fontes, 2003.

SMITH, A riqueza das nações: investigação sobre sua natureza e suas causas. v. 2. Trad. Luiz João Baraúna. São Paulo: Nova Cultura, 1996.

TJSC, Apelação n. 0003670-40.2010.8.24.0038, de Joinville, rel. Des. Luiz Fernando Boller, Primeira Câmara de Direito Público, j. 23-08-2016.

TJSC, Apelação Cível n. 0307715-15.2017.8.24.0023, da Capital, rel. Des. Cid Goulart, Segunda Câmara de Direito Público, j. 03-04-2018.

TORRES, R. L. A ideia de liberdade no Estado patrimonial e no Estado fiscal. Rio de Janeiro: Renovar, 1991.

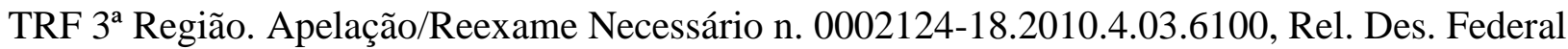
Johonsom Di Salvo, j. em 07-08-2012, e-DJF3 Judicial 1 DATA:14-08-2012. 